\title{
Trois figures de l'autorité masculine \\ dans « Magnus » de Sylvie Germain
}

Dr. Manal Zahran

Maître de conférences Faculté de pédagogieUniversité Ain ChamsDépartement de français

\begin{abstract}
$\underline{\text { Abstract }}$
Sylvie Germain est l'une des écrivains français qui ont réussi, grâce à son pouvoir créateur, à enrichir la littérature française par l'abondance de sa production littéraire distinguée et variée qui reflète une virtuosité remarquable d'une écrivaine prolifique. Paru en 2005, Magnus reçoit un accueil enthousiaste du public et le prix Goncourt des lycéens. Dans cette œuvre si riche, Sylvie Germain retrace l'itinéraire d'un orphelin amnésique qui essaie difficilement de récupérer son passé effacé par les grands chambardements de la Seconde Guerre mondiale. Enfant abandonné à la recherche de ses origines, Magnus rencontre plusieurs personnages masculins et féminins.
\end{abstract}

Notre étude portera sur trois figures de l'autorité masculine :

$\mathrm{La}$ première figure est celle $\mathrm{du}$ mal (la figure négative) incarnée par le médecin nazi Clemens Dunkeltal qui ne pense qu'à ses intérêts personnels au détriment de sa femme Thea et son fils adoptif Magnus.

$\mathrm{La}$ deuxième figure est celle du bien (la figure positive) incarnée par Lothar Schmalker qui a aidé Magnus à découvrir la vérité et les mensonges inventés par ses parents adoptifs.

La troisième figure est celle de la religion incarnée par frère Jean le vieil ermite qui a aidé le jeune homme à oublier le monde terrestre et à passer au monde céleste espérant trouver la paix perdue dans la vie.

L'analyse de ces trois personnages masculins, était l'objectif essentiel de notre étude.

Dans Magnus, Sylvie Germain ${ }^{1}$ retrace l'itinéraire d'un orphelin amnésique qui essaie difficilement de récupérer son passé effacé par les grands chambardements de la Seconde Guerre mondiale. L'étude de Magnus de Sylvie Germain nous ouvre plusieurs horizons qui méritent d'être découverts. Le roman explore les atrocités et les années sombres de la Seconde Guerre mondiale et ses conséquences désastreuses qui resteront gravées à jamais dans la mémoire de l'Histoire moderne.

L'écrivaine braque la lumière sur le spectacle horrible vécu en Allemagne sous la politique perverse et la série d'idéologies de la dictature nazie tels que le nazisme, la persécution des juifs, les rafles de la guerre, le régime totalitaire, la répression nazie des églises catholiques et protestantes et tant d'autres crimes commis par le régime hitlérien qui a bouleversé l'Allemagne toute entière par ses promesses de gloire, sa propagande imaginaire et ses rêves irréalisables. Magnus, 


\section{Dr. Manal Zahran}

le protagoniste du roman, est l'un des victimes de ce monde chaotique qui a perdu son identité, ses parents, sa langue et sa mémoire sous les bombardements de la Seconde Guerre mondiale.

Enfant abandonné à la recherche de ses origines, Magnus rencontre plusieurs personnages masculins et féminins, errants et raisonnables, positifs et négatifs. Parmi les personnages qui figurent dans le roman, nous avons choisi ceux qui ont exercé une autorité sur le protagoniste. Notre étude portera sur l'autorité masculine incarnée par trois personnages masculins qui ont joué un rôle considérable dans la vie du protagoniste et ont exercé une influence indélébile sur sa personnalité.

La première figure de l'autorité masculine est celle du mal (la figure négative) incarnée par le médecin nazi Clemens Dunkeltal, le père adoptif de Magnus et le premier personnage masculin dans sa vie.

Refusant l'idée de l'adoption, cet homme martial, n'a jamais accordé le moindre intérêt à l'intrus que sa femme stérile a insisté à adopter.

Ce manque d'affection manifesté à l'égard de cet orphelin âgé de cinq ans avait des conséquences néfastes qui méritent d'être étudiées ultérieurement.

Quant à la deuxième figure de l'autorité masculine c'est celle du bien (la figure positive) représentée par Lothar Schmalker le frère aîné de Thea la mère adoptive de Magnus, et le deuxième personnage masculin dans la vie de ce dernier. C'est Lothar qui s'est occupé de cet adolescent orphelin après la mort de sa mère adoptive et qui l'a aidé à découvrir la vérité et à sortir de ce monde fictif créé par ses parents adoptifs.

Quant à la troisième figure de l'autorité c'est celle de la religion incarnée par frère Jean qui a déployé un effort considérable à tendre ses mains au jeune homme pour l'aider à sortir de son monde terrestre et l'orienter vers le monde céleste où il peut trouver la paix perdue à cause d'une vie congénitalement absurde.

Pour mieux comprendre et analyser les caractères de ces trois personnages masculins et leur influence sur le protagoniste, il nous a paru qu'incorporer les théories de la psychanalyse dans notre recherche serait logique et utile.

En effet, il existe une relation étroite entre la littérature et la psychanalyse que Bellemin-Noël explique ainsi : «la relation entre la psychanalyse et la littérature est à double sens : chacune emprunte et prête à l'autre, toutes les deux trouvent un bénéfice dans cet échange » (Bellemin-Noël, 1999 :48).

Bref, l'approche psychanalytique serait une méthode efficace qui nous aidera à mieux éclaircir et à mieux étudier les caractères de ces personnages masculins.

\section{I-Clemens Dunkeltal (la figure négative)}

\section{1-Le rêve de la Seconde Guerre mondiale.}

Clemens Dunkeltal, le père adoptif de Magnus, est un médecin nazi qui exerce son métier dans les camps de concentration d'Hitler qui incarne la barbarie et l'inhumanité au sens stricte du terme. Egoïste et opportuniste, Clemens qui ne pensait qu'à ses intérêts personnels, «était surtout flatté de pouvoir entrer dans la famille du professeur Schmalker» (Germain, 2005 :56), le père de son épouse Thea et son professeur à l'université de médecine. Pour satisfaire ses ambitions 
politiques et professionnelles, Clemens n'a pas hésité un instant de guetter l'occasion et d'épouser Thea la romantique qui était follement éprise de lui et l'année de leur mariage «fut pour lui fastueuse: il devint le gendre d'un éminent professeur, et prit sa carte au parti national - socialiste des ouvriers allemands dirigé par son mentor Hitler.» (Germain, 2005 : 56)

Fasciné par les promesses fallacieuses et les rêves de grandeur et de splendeur créés par le Führer qui incarnait le rêve d'un Reich millénaire qui va s'étendre immensément dans l'espace et le temps, Clemens éprouve un enthousiasme aveugle pour le régime hitlérien et manifeste une fierté sans égale pour son adhésion au parti nazi.

Fier d'être l'un des membres d'un parti puissant comme le parti nazi, cet homme belliqueux, rêvant d'une victoire glorieuse, d'un Reich conquérant et d'un avenir brillant, exprime sa fierté et son optimisme à travers les soirées magiques qu'il organisait chez lui à la maison où «il se transfigure en roi prodigue, lorsque, accompagné au piano par sa femme ou par un des amis invités à dîner, il se campe au milieu du salon, [...], et chante des airs de Bach, de Schütz, [...] de sa voix de baryton basse douée d'une étonnante plasticité». (Germain, 2005 :20)

Pour mieux comprendre le sens du rêve qui obsède Clemens, nous avons eu recours à la psychanalyse qui nous explique le rêve ainsi «Pour Sigmund Freud et selon le principe du déterminisme psychique, le rêve, loin d'être un phénomène absurde ou magique, possède un sens : il est l'accomplissement d'un désir. Il a pour fonction de satisfaire le rêveur. Cette fonction du rêve constitue en fait une mine de renseignements quant aux désirs du rêveur. Selon Freud, le rêve est l'accomplissement d'un désir inconscient». (Freud, 2003 : 129) Les rêves de gloire et de puissance ont poussé cet homme martial à aller droit son chemin écrasant tout ce qui pouvait entraver sa marche vers ces aspirations. Rien n'est plus brutal que la participation de ce criminel de guerre à «l'extermination de nombreux prisonniers en leur administrant une piqûre de phénol dans le cour». (Germain, 2005 : 43)

Ses penchants politiques vont de pair avec les idées de son épouse Thea qui, manifestant une ardeur aveugle et une fierté incomparable pour le régime hitlérien, «approuvait sans réserve tout ce que déclarait et entreprenait son mari». (Germain, $2005: 56$ )

Respectant le moule où le régime hitlérien a coincé la femme allemande, Thea a accepté aveuglément l'idéologie délétère imposée par ce régime qui a pour objectif de cantonner la femme dans le rôle d'épouse obéissante et de mère dévouée et l'obliger à suivre l'adage de l'ancien empereur Guillaume II «Kinder, Küche, Kirche ${ }^{2}$ » qui signifie que les enfants, la cuisine, et l'église doivent être la préoccupation dominante de toute femme allemande. Pour se conformer à l'idéal féminin du régime nazi, Thea, qui souffre d'un cas de stérilité incurable, s'est occupée favorablement de ses deux jeunes frères jumeaux Franz et Georg qui étaient membres de la jeunesse hitlérienne et «qui avaient Hitler pour dieu Clemens pour modèle, et la guerre pour vocation». (Germain, 2005 : 59) La mort de ses frères jumeaux à la guerre a bouleversé la jeune femme stérile qui « [...] depuis longtemps avait volé à Friedericke (sa mère) son rôle de mère auprès des 


\section{Dr. Manal Zahran}

jumeaux auxquels elle vouait un amour jaloux». (Germain, 2005 : 61).

Pour combler le vide maternel que ses frères ont provoqué après leur mort, Thea, «défiant pour la première fois son mari, qui lui, ne désirait nullement recueillir un enfant inconnu» (Germain, 2005: 116), a décidé d'adopter un enfant. En choisissant l'enfant adoptif, Thea, représentant toujours le modèle idéal de la mère nazie, a pris en considération l'objectif de Führer de «purifier la race aryenne ${ }^{3} \gg$.

Cette idéologie raciste l'a poussée à choisir un garçon «en parfaite conformité avec les normes aryennes, [...]. Sain de corps et de race; quant à l'esprit, il est nu, page gommée prête à être réécrite. La femme se chargera de la blanchir à fond avant d'y écrire à sa guise, elle dispose d'un texte de rechange. Un texte de revanche sur la mort». (Germain, $2005: 101)$

A tous ces privilèges, s'ajoute le choix de son prénom. Pour glorifier le souvenir de ses deux frères jumeaux tués à la guerre, Thea, estimant leur sacrifice, tient à donner leurs prénoms à son fils adoptif en l'appelant Franz Georg et oblige le petit à «leur témoigner fierté et gratitude, à jamais. Car c'est pour lui qu'ils se sont sacrifiés [...], pour qu'il grandisse dans un pays de gloire et de puissance». (Germain, $2005: 14$ )

Cet enfant adoptif orphelin, âgé de cinq ans qui ne possède de son passé que son ourson Magnus et dont Thea «ignorait l'origine, sinon qu'il était rescapé d'une ville bombardée», (Germain, 2005 : 118) était mal accueilli par Clemens qui, estimant la politique hitlérienne qui encourage le peuple à avoir des enfants, «venait d'avoir un enfant illégitime, certes, mais bien de lui» (Germain, 2005 : 117). Cet enfant bâtard justifie son refus obstiné d'adopter un enfant inconnu et de maltraiter l'enfant que sa femme a adopté.

A maintes reprises, Sylvie Germain nous souligne le grand fossé qui sépare Clemens de l'enfant orphelin que sa femme a insisté d'adopter. Refusant l'idée d'accueillir un enfant inconnu au sein de la famille, Clemens «n'accorde que peu d'attention à son fils. Jamais il ne joue avec lui, ni ne lui raconte des histoires, et quand il daigne s'intéresser à lui, c'est pour lui reprocher sa passivité» (Germain, 2005 : 19)

Cependant, ce manque d'affection et ce sentiment d'indifférence absolue manifesté à l'égard de cet intrus n'a jamais empêché le petit d'admirer la voix de baryton de son père en chantant devant ses amis qu'il invitait à passer chez lui des soirées magiques. «C'est pour cette voix-là, celle des soirs enchantés, que FranzGeorg aime son père, et l'admire sans mesure. Tant pis si ce père ne se montre guère affectueux, même si cela le blesse; son chant suffit à le consoler de cette peine, ou du moins il la transforme en mélancolie bienheureuse. Son père est distant, mais son chant est un abri, une jouissance. Il porte un soleil nocturne dans sa poitrine». (Germain, $2005: 21$ )

Rien n'est plus expressif que ce souvenir pénible du zoo de Berlin où Clemens avait emmené le petit Franz-Georg un jour. "C'était si exceptionnel que son soi-disant père s'occupât de lui, que cette journée l'avait profondément marqué, d'autant plus que son bonheur de se trouver enfin seul avec «son maître de la nuit » avait été d'emblée piétiné». (Germain, 2005 :127) Malheureusement cette promenade n'était qu'un prétexte pour que Clemens, l'infidèle à sa femme, 
puisse sortir avec sa maîtresse et son fils illégitime Klaus âgé de trois ans et dont personne ne connaissait rien du tout et dont Franz-Georg était jaloux. "Ce n'était cependant pas la présence importune de cette femme volubile qui avait gâché sa joie d'enfant, mais celle du gamin, [...], auquel le «maître de la nuit» avait manifesté bien plus d'attentions et d'affection qu'il n'en avait jamais témoigné à son propre fils». (Germain, 2005 :127)

Ajoutons à cette relation distante dépourvue de toute sorte d'affection et de tendresse à l'égard de l'enfant, l'absence constante du père qui a dressé un mur infranchissable entre eux ce qui a contribué à laisser le champ libre à sa mère Thea pour le former à sa guise. Sans faire la moindre allusion à son fils qu'il est adoptif, Thea «consacre tout son temps à rééduquer son enfant oublieux et mutique, [...]. Elle le remet au monde une seconde fois, par la seule magie de la parole». (Germain, $2005: 13$ ).

Leurrée par des espérances vaines, Thea, vivant dans des illusions, a déployé tout son effort à détourner l'esprit de son enfant adoptif en nourrissant sa pensée par des mensonges et des chimères qui traduisent son errance et son incapacité à distinguer entre le vrai et le faux. Cette errance que Berthet considère «synonyme d'une forme de tromperie, consiste à dissimuler le passé, à prendre le faux pour le vrai, à s'égarer dans le mensonge - et à transmettre ce mensonge». (Berthet, 2007 : 10)

Les mensonges de Thea commencent par sa tentative de faire comprendre à son fils qu'il a perdu sa mémoire sous l'effet d'une fièvre vorace, or, ce sont les bombardements de la Seconde Guerre mondiale qui l'ont rendu orphelin et amnésique. Fière de «l'épopée familiale pleine de noblesse et de tristesse» (Germain, 2005 :14), Thea tient à présenter de sa famille les membres éprouvant un enthousiasme aveugle pour le régime hitlérien et dont chacun «a une stature de héros : lui en tant que victime d'une fièvre vorace qu'il a cependant réussi à vaincre, sa mère en tant que fée bienfaisante, son père en tant que grand médecin. A ce trio s'ajoutent deux autres figures, bien plus valeureuses et admirables encore celles des jeunes frères de sa mère, tués à la guerre, [...]. De ces deux héros dont il porte les prénoms, il se laisse avec docilité transmuer en mausolée vivant». (Germain, 2005 : 14). Pour glorifier la figure du père, toujours absent, aux yeux de son fils, Thea le laisse imaginer que son père «le docteur Clemens Dunkeltal doit être un homme important - un magicien de la santé. Il reçoit des patients par milliers, dans son vaste asile de la lande, et tous souffrent certainement de maladies contagieuses puisqu'ils n'ont pas le droit de sortir». (Germain, 2005 : 19).

C'est ainsi que Clemens, enivré de sa déesse guerre, est resté aux yeux de Franz-Georg, grâce aux mensonges de Thea et son errance elle-même, un médecin noble et dévoué digne d'estime et de respect puisqu'il s'ingénie à apaiser les souffrances et les douleurs des malades, et son maître de la nuit qui le fascine avec sa voix charmante.

\section{2-L'effondrement du rêve et son impact sur Clemens}

La défaite d'Hitler vers la fin de la Seconde Guerre mondiale et la décadence de son système pervers ont bouleversé la vie de Clemens. Ce n'est 


\section{Dr. Manal Zahran}

qu'après la mort d'Hitler et la chute de son régime intransigeant que cet homme belliciste commence à comprendre que toutes les promesses de gloire et tous les rêves de puissance et de grandeur n'étaient qu'un mirage et des illusions et que lui-même était parmi les victimes d'un monde chimérique, d'une politique raciale et d'une croyance fausse forgés à travers la propagande splendide que le Führer a présentée dans son œuvre «Mein kampf ${ }^{4}$ »

Le danger qui croît de jour en jour après la défaite de Führer, a jeté l'horreur dans le cœur de ce monstre au point d'être paralysé, incapable d'agir et de devenir une proie facile à être dévorée par une vive anxiété. «Condamné par contumace à la prison à vie» (Germain, 2005 : 43), ce criminel ignoble, obligé à tout changer :

ses vêtements, son comportement et même sa façon de saluer ses amis, a décidé de s'enfuir. «Une nuit de mars, les Dunkeltal s'enfuient de leur maison avec une discrétion de voleurs. [...]. Ils vont vers le sud. [...], tant le chemin est long, tout en zigzags et en panique.[...]. Ils errent à travers le pays délabré, traversent des villes et des villages en ruines, croisent des hordes de gens hagards. Parfois ils se terrent plusieurs jours dans une cave, ou dans une grange. Ils ont faim, mais la peur les harcèle plus encore». (Germain, 2005 : 26-27). Pour éviter toute sorte de danger, Clemens, saisi par un état de panique et de terreur indescriptible, se trouve obligé de changer son nom, même celui de sa femme Thea et de son fils Franz-Georg. «Ils ont tout perdu, même leurs noms; ils ont troqué celui de Dunkeltal contre Keller - les parents s'appellent désormais Otto et Augusta Keller et Franz - Georg, simplement Franz Keller. Seul l'ours Magnus a le droit de conserver intacte son identité.» (Germain, 2005 :27)

Cherchant la paix et la sécurité, Clemens submergé par «une nervosité croissante, un air traqué et hargneux» (Germain, 2005 :25), se sépare de sa femme et de son fils pour se cacher et les laisse poursuivre seuls leur voyage interminable vers le sud espérant les rejoindre le plus tôt possible.

Cette première séparation a exercé une influence considérable sur sa femme Thea ainsi que sur son fils qui «ressent douloureusement cette séparation.» (Germain, 2005 :28)

Sa femme Thea, ou bien Augusta après la modification de son prénom, a essuyé l'amertume de l'abandon inattendu de son mari qui l'a jetée par son absence dans un labyrinthe dont elle ne peut pas sortir. Pour mieux comprendre cet état de souffrance qui a saisi Thea après le départ de son mari, nous avons eu recours à la psychanalyse qui appelle cet état de souffrance «névrose d'abandon où prédominent l'angoisse de l'abandon et le besoin de sécurité [...]. Les sujets présentant cette névrose sont nommés abandonniques.[...], le besoin illimité d'amour, [...] signifierait une recherche de la sécurité perdue [...]. Enfin on devrait invoquer un facteur constitutionnel psycho- organique (gloutonnerie affective, intolérance aux frustrations, déséquilibre névro-végétatif). [...]. La névrose d'abandon devrait être rapportée à une "perturbation du moi»qui n'apparaît souvent qu'au cours de la cure psychanalytique». (La Planche, 1996 : 273)

Tel était le cas de Thea ou bien Augusta. Après la fuite de son mari «Augusta Keller se montre un double assombri de l'aimable Thea Dunkeltal. Elle 
a perdu sa belle maison, son statut social, et son cercle de connaissances [...]. Elle a surtout perdu son rêve de grandeur qui l'aidait à supporter avec bravoure son chagrin de sœur amputée de ses deux cadets, [...]. Le Führer est mort. [...] et avec lui a sombré le Reich millénaire après une dérisoire douzaine d'années. Il ne reste plus rien de ses deux passions mêlées, la patriotique et la fraternelle, rien que des débris, des cendres et des ossements. [...] Elle se sent scandaleusement flouée, volée et au fil des jours son affliction s'empoisonne d'aigreur». (Germain, 2005 : 31-32)

Pour surmonter cette dépression nerveuse, la jeune femme, armée de volonté, de persévérance et de patience, a décidé de lutter contre le danger espérant trouver une issue à cette impasse jusqu'à l'arrivée de son mari. Soumise à ces circonstances pénibles, Thea la femme riche et l'élégante d'autrefois, trouve grâce aux relations que son mari avait à Friedrichshafen la ville où elle s'est enfuie pour s'installer, «une chambre où se loger avec son fils, [..] et un emploi de cuisinière dans un hôpital ; le salaire est dérisoire, mais le poste idéal pour glaner de quoi ne pas dépérir de faim». (Germain, 2005 : 32)

Cette attente angoissée est enfin interrompue par l'apparition soudaine de Clemens Dunkeltal dont l'aspect humiliant a choqué sa femme et a effrayé son fils. «Otto keller n'est pas même un double affaibli du puissant Clemens Dunkeltal, mais une contrefaçon pitoyable; il s'est rabougri en un fugitif crasseux, très amaigri, mal rasé, au regard de bête traquée, mauvaise». (Germain, 2005; 33) Malgré cette apparence vexante et effroyable de Clemens, son fils Franz, croyant toujours que Clemens est son père biologique, éprouve un bonheur extrême de revoir son père vivant. " [...], ce n'est pas grave, tout ce qui arrive, et que surtout il l'aime toujours, peut-être même davantage. Oui, davantage, car désormais, la pitié à l'égard de son père prime sur la crainte que celui-ci lui inspirait du temps de sa superbe». (Germain, 2005 : 34)

Malheureusement le bonheur de Franz n'a pas duré longtemps. Menacé par la prison à vie, le père Clemens a réussi à préparer l'argent et les papiers nécessaires pour partir tout seul au Mexique où il peut vivre sans danger en cachette sous son nouveau pseudonyme Helmut Schwalbenkopf, tout en promettant à sa femme et à son fils de le rejoindre lorsqu'il pourra trouver un endroit paisible et sain. Ce deuxième départ inattendu et plus tendu encore que la fois précédente était suffisant pour affaiblir et anéantir Thea qui «se corsète à nouveau de patience, mais sous le poids de la fatigue et de l'anxiété qui vont croissant au fil des jours, elle devient dure et irritable». (Germain, 2005 : 37). L'état psychique de Thea s'aggrave de plus en plus sous l'effet de l'attente anxieuse de son mari. Incapable de supporter la souffrance et la peine provoquées par l'amertume d'une attente prolongée et désespérée de son mari, Thea se trouve, malgré elle, saisie par un état de grande nervosité qui la rend incapable de contenir sa colère comme une folle irresponsable de ses actes. Dans cette optique, la psychanalyse nous explique la relation étroitement liée entre la maladie mentale et la névrose «Pour la psychanalyse, la maladie mentale est liée aux pulsions et à leur impossibilité de se satisfaire face aux répressions venant du Moi ou de la réalité extérieure ou encore du fait que les pulsions une fois fixées, ne veulent plus changer». (Mucchielli, 1993 : 23). Tel était le cas de Thea après le 


\section{Dr. Manal Zahran}

départ de son mari. L'état de fureur indescriptible qui l'a submergée, s'est reflété sur sa relation avec son fils adoptif. «Elle cesse de cajoler son fils et se met de plus en plus souvent à lui faire des reproches; [...]. Elle reprend à son compte les critiques et la rudesse du père à l'égard du garçon». (Germain, 2005 : 37).

Avec l'impatience grandissante d'une détenue, Thea s'est mise à compter les jours qui s'écoulent avec lourdeur et avec lenteur en attendant l'arrivée de son mari absent mais en vain. Malgré la solitude et la faiblesse qui exacerbent encore plus sa santé psychique et physique, Thea n'a jamais perdu l'espoir de rejoindre son mari. Enfin l'attente de Thea est interrompue par la nouvelle qui lui annonce la mort de son mari. «le dernier nom d'emprunt sous lequel il se cachait au moment de sa mort était Felipe Gómez Herrera». (Germain, 2005 :45) Ebranlée par cette catastrophe, la jeune femme a sombré dans le désespoir et les méandres de la folie. Frustrée par la ruine de son pays et l'effondrement de ses rêves, Thea découvre qu'elle a tout perdu : ses parents qui sont morts sous les bombardements de Berlin, ses deux jeunes frères qui sont tués à la guerre et enfin son mari qui s'est enfui pour trouver sa mort inattendue après trois ans d'absence et d'errance dans plusieurs pays. Rien ne lui reste. «La veuve réintègre son nom de Thea Dunkeltal, [...] elle n'a plus rien à craindre, donc plus rien à dissimuler.[...]. Dans le désert où elle se retrouve prisonnière, la veuve Dunkeltal se met à tourner en rond. Des cercles de plus en plus étroits, qui se font bientôt étouffants.» (Germain, 2005 :46)

Arrivée au comble de la déception et du désespoir la jeune veuve s'est soumise à la maladie qui la dévore lentement sans la moindre résistance de sa part. Malgré sa souffrance d'asthme, Thea refuse obstinément de se soigner et elle préfère mourir en silence. «Elle chemine à pas de mule vers sa propre extinction [...]. Elle s'était déprise. Déprise de tout, de l'envie de lutter, du goût de vivre, de la force d'aimer autant que de haïr. Elle n'attendait plus rien, ni pardon ni pitié de qui que ce soit.[...]. Elle était descendue dans les bas-fonds du vide et s'apprêtait à mourir en tout indifférence à elle-même». (Germain, 2005: 46-118)

Dans cette optique, Isabelle Dotan nous souligne que «Thea fait partie d'un groupe de personnages germaniens qui se laissent prendre par le malheur parce qu'ils sont trop faibles pour faire autrement: Face à une douleur trop forte, ils sont comme paralysés, incapables de réagir, ni par la fuite, ni par l'isolement. Ils entrent dans un processus d'inhibition, c'est - à - dire une diminution des fonctions vitales qui escamotent l'angoisse.[...]. Ces êtres $s$ 'assujettissent à un processus d'inhibition comme une forme de protection en se laissant sombrer dans la folie et/ou la mort». (Dotan, 2008 :266)

Quant à Franz, cet enfant dont l'âge ne dépasse pas les neuf ans, il n'arrive pas à comprendre le monde chaotique qui l'entoure. La déchéance et la fuite de son père ainsi que la faiblesse de sa mère l'ont jeté dans un labyrinthe dont il est difficile de sortir. Ses parents n'ont jamais essayé de lui expliquer les vrais motifs qui les ont poussés à modifier leurs noms et à quitter leur maison et leur ville. «Ses parents [...], se contentant de lui interdire toute allusion à son véritable nom, à la maison qu'ils ont quittée, à la région où ils vivaient, et même au métier de son père. L'enfant écoute les ordres qui lui sont chuchotés sur un ton de confidence impérieuse, et obéit sans discuter». (Germain, 2005 : 27) 
Malgré la défaite d'Hitler, la fuite de Clemens et les paysages de désastre qui ont choqué l'enfant, Thea, errante elle-même, continue à inventer des histoires à son fils et «lui ressasse à voix douce l'épopée familiale pourtant si mise à mal. Elle brode, elle enlumine le passé, elle estompe autant qu'elle le peut les souvenirs des dernières semaines et promet un futur radieux». (Germain, $2005: 32$ )

Entouré par un paysage de ruines et de destruction qui dépassait son entendement, le jeune Franz, aveuglé par sa mère, cherche une explication logique pour ce chambardement. Cependant sa mère n'a jamais essayé de le lui expliquer au contraire «elle refuse d'en discuter, elle s'acharne même à nier les faits, allant jusqu'à taxer les informations de mensonges, et de trucages les photographies divulguées», (Germain, 2005: 39).

Cet état d'errance qui a submergé le jeune Franz l'a poussé à se poser des questions au sujet de son père qui est déclaré «criminel de guerre» (Germain, 2005 : 39) et poursuivi par les autorités depuis la fin de la guerre. Cette expression était tellement mystérieuse pour qu'un enfant âgé de neuf ans puisse comprendre le sens.

Cet enfant naïf ne parvient pas à croire que son père le docteur Clemens Dunkeltal le magicien d'autrefois qui soignait des malades par milliers dans son camp où il exerçait sa profession, est devenu un criminel. L'image honorable que Franz garde de son père, le pousse à chercher une cause logique et suffisante pour toutes les accusations portées contre lui.

La perplexité et la stupeur de Franz sont arrivées à leur comble quand il a appris la mort inopinée de son père suicidé après une fuite de près de trois ans au Mexique sous le pseudonyme Felipe Gómez Herrera. Ce coup de foudre a ébranlé le petit qui, incapable de comprendre les circonstances de la mort de son père, s'est jeté dans la solitude absolue et il «se replie sur lui-même, plus seul et désemparé que jamais. C'est un repli sur du vent, car il vit dans un sentiment aigu de non sens et de précarité». (Germain, 2005 :46)

Cet état de désarroi et de solitude qui a assiégé Franz n'était qu'une conséquence normale de son incompréhension. Il souffre d'un malaise quand il se remémore la déchéance de son père en fantôme «Oui, le père n'est plus qu'un fantôme errant au-delà des mers» (Germain, 2005: 48) et il se demande «comment est-il possible que cette voix massive qui avait le don de l'envelopper d'une peau d'ombre et de vent plus ample et tendre que la nuit, ait hurlé l'épouvante à la face de centaines, de milliers de prisonniers, les ait exterminés?»(Germain, 2005 :48)

L'embarras et la souffrance qui s'emparaient de Franz sont interrompus par l'apparition fortuite de son oncle Lothar que la mère, déprise de sa vie errante, et dont «la mort chuinte déjà dans sa voix exténuée.» (Germain, 2005 :50), avait appelé pour lui confier son fils adoptif.

\section{3-Le destin de Clemens Dunkeltal}

Après avoir découvert la vérité douloureuse de «la face cachée de ce Reich que célébrait sa mère et que son père a servi avec une abjection zélée», 


\section{Dr. Manal Zahran}

(Germain, 2005 :55) Franz l'adolescent de treize ans éprouve une invincible répugnance à l'égard de ses parents et surtout son père qu'il a tant aimé et a tant admiré sa voix. «En lui, le fils mystifié, abandonné et surtout insupportablement souillé par cette filiation». (Germain, 2005 : 65)

Pour supprimer ce passé déshonorant, le jeune adolescent, essayant de chercher une nouvelle identité, remplace son prénom choisi par sa mère adoptive par Adam. La haine implacable qu'Adam manifeste à l'égard de son père suicidé au Mexique 1'a poussé à apprendre 1'espagnol. «[...] : il veut parvenir à maîtriser parfaitement la langue du pseudo-Felipe Gómez Herrera pour dominer le fantôme de cet assassin dont les crimes demeurent à jamais impunis, [...]. En fait, il aimerait pouvoir dissoudre ce père dans les mots qu'il conquiert avec pugnacité comme dans un acide.» (Germain, 2005 : 65-66)

La maîtrise de la langue espagnole n'était pas suffisante pour satisfaire son désir acerbe de se venger de son père fugitif. Saisi par un besoin impérieux de chercher ce criminel, Adam, poussé par la haine et la rancune, est parti à l'âge de vingt ans pour cinq semaines au Mexique espérant obtenir des renseignements sur les derniers jours du fuyard dont il ignore les circonstances de la mort. Malheureusement l'errance d'Adam au Mexique et en particulier dans la ville de Veracruz où son père a préféré se cacher que d'affronter la justice était infructueuse et sans profit. Cependant, Adam, obsédé par l'idée de retrouver son père, a décidé, sans jamais s'abandonner au désespoir, de continuer son vagabondage au Mexique et de partir au village de Comala qu'il a découvert à travers un roman mexicain de Juan Rulfo intitulé Pedro Páramo. Ce roman relate l'histoire du personnage «Juan Preciado parti sur les traces de son père qu'il n'a jamais connu, un certain Pedro Páramo qui régna en petit despote dévoré d'ambition et de goût du pouvoir dans le village de Comala. Mais Comala n'est plus qu'un village perdu hors du temps et de la vie, [...]» «on y est sur les braises de la terre, dans la gueule même de l'enfer». (Germain, 2005 :85)

La ressemblance frappante entre les circonstances de Juan Préciado le héros de Juan Rulfo et celles d'Adam, a encouragé ce dernier à marcher dans les pas de son compagnon d'infortune Juan Préciado et à partir à Comala. «Juan Préciado est son double, son guide dans les décombres de la mémoire, dans le labyrinthe de l'oubli. Et Pedro Páramo, odieux caudillo de province, homme brutal et hautain, est l'ombre portée de Clemens Dunkeltal dans Comala, village de nulle part, de partout, lieu insituable et obsédant». (Germain, 2005 : 85-86)

Soumis à son obsession de trouver son père, le jeune homme s'est mis à parcourir à grands pas une terre inconnue. «Il avance à pas zigzagants forcenés. Il est un pèlerin de colère venu tordre le cou au spectre paternel, et aussi bien à l'enfant niais qu'il fut et qui aimait ce père». (Germain, 2005 :89)

Epuisé par son errance dans le village de Comala, le jeune homme, sous l'effet de la chaleur intense du soleil, est tombé victime d'une insolation. La fièvre vorace qui l'a attaqué était suffisante pour ébranler sa mémoire et voir fulgurer son passé. Ce sursaut de mémoire lui a permis de se rappeler le spectacle horrible vécu pendant la Seconde Guerre mondiale en Allemagne où il a perdu sa mère biologique sous les bombardements qui ont anéanti entièrement la ville 
allemande Hambourg au point de la transformer en cendres.

De même, sous l'emprise de la fièvre et à force de tension, la mémoire du jeune homme s'est remise en mouvement pour découvrir que la femme élégante qui s'est présentée dans le centre où il a été placé après ce paysage de ruines, pour l'adopter, était Thea. Cette découverte stupéfiante était tellement douloureuse qu'elle a paralysé sa réflexion et l'a rendu incapable de réagir. "Car lui aussi, lui plus que quiconque, aimerait savoir qui il est exactement. Pour l'heure, il sait seulement qui il n'est pas qui il n'aura jamais été et ne croira plus jamais être le fils des Dunkeltal. Une délivrance» (Germain, 2005 :109-110).

Saisi par un sentiment d'aversion à l'égard de ses faux parents «Thea et Clemens Dunkeltal la folle et l'assassin»(Germain, 2005 : 148), le jeune homme, sous le nom de son ours en peluche résidu de son passé «Magnus» s'est mis à jongler avec ses soupçons et avec son héritage souillé par une longue imposture à travers plusieurs pays et plusieurs langues espérant mettre fin à son errance et trouver son identité perdue sous les ténèbres de la barbarie de son siècle. C'est ainsi que «l'errance de la mère oblige l'enfant à vivre l'errance de deux façons différentes : premièrement en tant qu'égarement par rapport à ce qui est vrai et, ensuite, en tant que quête identitaire d'origines». (Rogowska, 2009 : 38).

Après plus de trente ans de vagabondage autour du monde, le fantôme du passé resurgit à la surface du présent pour choquer Magnus qui demeure éberlué devant le miracle dont il a tant rêvé. Le spectre paternel que Magnus a tant cherché au Mexique pour se venger de lui est enfin apparu par hasard dans un restaurant à Vienne où le fuyard vient souvent avec son fils Klaus pour présenter des chansons populaires sous le nom de Walter Döhrlich. L'apparition fortuite du fugitif après plus de trente ans a attisé les soupçons de Magnus qui ne parvenait pas à croire cette surprise choquante.

Malgré la ressemblance flagrante entre le vieux chanteur qui chante devant ses yeux et le salaud d'autrefois dont il admirait la voix, Magnus reste incertain et incapable de chasser ses soupçons. Pour obtenir une preuve qui démontre que ce vieux chanteur est le fuyard Clemens Dunkeltal avec sa voix de baryton, Magnus a eu recours au serveur du restaurant qu'il a chargé de remettre à ce vieux chanteur un message où il dévoile avec humour la vraie personnalité que le vieux Clemens, pourchassé par les autorités, s'est ingénié à cacher sous plusieurs pseudonymes Otto Keller, Helmut Schwalbenkopf, Felipe Gómez Herrara et enfin Walter Döhrlich. Incapable de dominer sa colère, Magnus, avec un ton insultant et menaçant et avec la fierté d'un vainqueur, rappelle à son destinataire ses crimes commis dans les camps de concentration d'Hitler affirmant que le temps de son châtiment est arrivé et qu'il ne peut plus s'enfuir cette fois-ci de la justice. Le contenu de ce message envoyé par Magnus a effrayé le vieux clemens qui, ignorant encore le destinateur du message, se trouve saisi par un état d'irritation incomparable. "Aussitôt son sourire se fige, son visage vire au blême, ses traits se plombent. [...], les yeux plissés de fureur. Mais il y a aussi de la frayeur dans son regard d'imposteur démasqué. Le regard de Clemens Dunkeltal du temps de sa fuite à la fin de la guerre». (Germain, 2005 : 220)

Après avoir obtenu la preuve qu'il cherchait, Magnus, craignant que le vieux cabotin pouvait le rejoindre, a pris soin de s'éloigner du quartier où il 


\section{Dr. Manal Zahran}

habitait mais en retard. Le vieux chanteur, après avoir pris les informations nécessaires sur l'auteur du message injurieux auprès du serveur qui le lui a remis, a compris qu'il est en danger. Menacé par ses innombrables crimes commis dans le passé, le vieux criminel de guerre, n'a pas hésité un instant de poursuivre son destinateur menaçant pour l'écraser avec sa voiture qui s'est précipitée sur lui afin de l'assassiner. Cet accident brutal a provoqué la mort du chauffeur qui était Klaus le fils illégitime de Clemens et l'importun du zoo de Berlin d'autrefois. Tandis que Magnus et le vieux Clemens tous deux sont transportés à l'hôpital. «le premier a une hanche et un fémur fracturés, le second la colonne vertébrale brisée» (Gemain, 2005 : 226)

Désespéré de sa vie inutile après la mort de son fils unique, le vieux Dunkeltal le robuste d'autrefois, incapable de supporter sa prison dans son fauteuil d'invalide, a décidé d'ajouter à ses crimes indélébiles d'autrefois un ultime en se suicidant par un poison qui lui a permis de mettre fin à son passé honteux et son présent menacé, sous le masque du charmant walter Döhrlich sans être présenté à la justice ou jugé pour ses crimes impardonnables commis contre l'humanité. Par la mort de ce personnage maléfique qui représente la figure du mal, Magnus abaisse les rideaux sur une période critique de sa vie marquée par l'errance, les mensonges et l'inhumanité au vrai sens du terme.

\section{II-Lothar (la figure positive)}

\section{1-L'apparition inattendue de Lothar dans la vie de Magnus.}

Lothar est le deuxième personnage masculin qui a exercé une influence de première importance sur la vie de Magnus. Lothar Benedikt Schmalker est le frère aîné de Thea la mère adoptive de Magnus. Son intérêt pour la théologie lui a permis de faire la connaissance de Dietrich Bonhoeffer ${ }^{5}$ lors de ses études à l'université de Berlin en 1925 et de rejoindre les rangs des opposants pour organiser une résistance contre le régime nazi qui a voulu étouffer les Églises du pays catholiques et protestantes et obliger «Les Églises Luthériennes», à s'unifier en «Église allemande» d'où tout «non aryen » était exclu» (Germain, 2005 :57). Cette hostilité hitlérienne manifestée envers les Églises a encouragé Lothar à organiser des séminaires clandestins avec «quelques puissantes personnalités, [...] donnant naissance à « L'Église confessante ». (Germain, 2005 : 57)

L'adhésion de Lothar à L'Église confessante qui «s'accommodait plutôt mal au credo sauvage» (Germain, 2005: 57) imposé par le régime nazi a détérioré sa relation avec sa sœur Thea et son beau-frère Clemens qui, nazi fanatique, transformait toute discussion entre eux en dispute. Le désaccord entre Lothar et sa sœur Thea atteint son paroxysme quand celui-ci a décidé de se marier avec Hannelore qui appartient à une famille juive et non aryenne. Ce mariage, transgressant la politique brutale d'Hitler, a approfondi le fossé entre Thea et son frère aîné Lothar qui a décidé de rompre sa relation avec sa sœur et son beaufrère Clemens «qu'indisposait très fâcheusement ce parent séditieux, accroché à sa Bible comme un âne à son piquet, et de surcroît marié à une juive». (Germain, 2005 : 58)

La répression nazie est devenue plus dure et plus cruelle quand Hitler a négligé l'encyclique «Avec un souci brûlant» (Germain, 2005 : 59) que l'Église 
catholique a publiée selon le concordat qu'elle a signé avec l'Etat nazi. En outre, la barbarie hitlérienne, écrasant tout ce qui pouvait entraver son chemin, a commencé à arrêter et à enfermer aux camps de concentration beaucoup de pasteurs de l'église confessante.

Menacé par la persécution du régime hitlérien féroce qui lui a interdit toute activité pastorale et inquiet pour sa femme et l'avenir de ses deux filles, Lothar, désespéré de récupérer l'Allemagne de la tyrannie et le despotisme de Führer surtout après la disparition d'un grand nombre de ses amis, a décidé d'émigrer en Angleterre espérant retourner en Allemagne après la défaite d'Hitler et la chute de son régime. Après douze ans d'émigration, Lothar est revenu à son pays natal l'Allemagne sous la pression de sa sœur Thea qui, à l'approche de la mort, trouve que «seul le frère qu'elle avait violemment rejeté lui paraissait digne de confiance» (Germain, $2005: 118$ ) pour lui confier son fils adoptif.

Malgré le différend idéologique qui sépare Lothar de sa sœur qui «l'avait insulté quand il s'était opposé au régime, méprisé quand il avait épousé une fille d'origine juive, puis traité de traître quand il avait émigré dans un pays ennemi» (Germain, 2005 : 117), Lothar par la sagesse d'un frère aîné responsable de sa sœur cadette et par la raison d'un pasteur consciencieux, n'a pas hésité un instant de répondre à l'appel de sa sœur et de revenir en Allemagne pour l'aider. Estimant l'état déplorable de sa sœur déprimée, Lothar, par pitié et par piété, a accepté de bon cœur d'assumer la responsabilité d'un enfant adoptif qu'il n'a jamais connu sans la moindre protestation de sa part, et de l'emmener chez lui au sein de sa famille avec sa femme et ses deux filles en Angleterre.

\section{2-Le rôle éducatif de Lothar}

Dès son arrivée en Angleterre avec son neveu, Lothar, devenu le tuteur de cet orphelin, était «soucieux avant tout de la bonne instruction scolaire, morale et religieuse de son neveu. Mais de structuration affective, aucune.»(Germain, 2005 : 74).

Pour éviter toute sorte de préjudice ou de problème, Lothar, par la prudence d'un père dévoué, conseille son neveu, dès son arrivée avec lui à Londres, de renoncer à son nom de famille paternelle de Dunkeltal et de prendre celui de sa famille maternelle de Schmalker.

Par l'intérêt d'un tuteur soucieux de l'avenir de son neveu, Lothar, sans jamais essayer de dévoiler le secret de sa sœur devant cet adolescent, lui propose avec une sollicitude paternelle de changer son prénom et de commencer une vie nouvelle avec une identité nouvelle sans penser à son passé douloureux plein d'épreuves et de souffrances.

Ignorant le vrai motif derrière les conseils de son oncle Lothar, FranzGeorg «ressent comme une agression ce deuxième bouleversement de son identité auquel on l'incite, [...]. Décidément, les adultes sont incompréhensibles et parfois terriblement agaçants. Après une longue et morose réflexion, il finit par opter pour un prénom qui passe partout - le premier de l'humanité : Adam» (Germain, 2005 : 54)

Sans la moindre intervention de sa part, Lothar éducateur responsable de sa mission n'a pas essayé d'imposer un prénom spécifique à son neveu et lui a 


\section{Dr. Manal Zahran}

laissé la liberté totale de choisir le prénom qui lui convient et le félicite de son choix. Dans cette optique, le professeur Marcelli nous souligne que «la bonne autorité est celle qui contient l'adolescent, le protège, le rassure. Cette gangue protectrice se construit tout au long de l'enfance, pour qu'un adolescent puisse accéder à une certaine autonomie, il est indispensable qu'il soit capable de se fixer lui-même des limites». (Marcelli, 2009 :157)

La tâche éducative que Lothar assume comme lui dicte son devoir pastoral était un lourd fardeau surtout que cet adolescent orphelin était la victime d'une longue imposture inventée par une mère errante et trompée et un père nazi, belliqueux et barbare. Educateur conscient de son rôle d'instituteur, Lothar tient à aider l'adolescent à sortir de ses ténèbres en lui révélant les raisons qui l'ont obligé à fuir l'Allemagne et à émigrer en Angleterre «C'est Lothar qui l'instruit progressivement des faits, étonné de constater à quel point l'enfant a été maintenu dans l'ignorance de presque tout, et aussi combien il s'est complu dans cette fausse ingénuité, même s'il en devine la cause.» (Germain, 2005 :55)

La réalité choquante était un coup de massue qui est tombé sur la tête de l'adolescent pour l'ébranler et le faire sentir qu' «il n'est qu'un greffon dans la famille de son oncle, un refugié. [...] Il n'est pas un fils, ne le sera jamais. Pire, il reste le rejeton d'un bourreau doublé d'un lâche, et d'une criminelle par complicité, sottise et vanité» (Germain, 2005 :74)

Ce sentiment étouffant qui a saisi l'adolescent après la découverte de la réalité se traduit en violente hostilité à l'égard de lui-même et à l'égard de ses faux parents. Dans cette optique, la psychanalyse nous explique cet état de violence ainsi «La plupart des personnages qui ont été maltraités dans leur enfance sont aujourd'hui des adultes très perturbés.[...] et la plupart des sujets dépressifs ou alcooliques ont été élevés dans un climat de violence et de terreur». (Samalin, 1996 : 189).

Cet état de fureur et d'agressivité a rendu l'adolescent incapable d'oublier son passé ou de pardonner ses parents. «Et leurs méfaits le lestent de honte, de douleur, de colère, [...] ; il est l'otage posthume de deux prédateurs auxquels la mort assure désormais une éternelle impunité, [...]. Qu'il y ait on non un jugement dans l'au-delà n'est pas son affaire, c'est ici et maintenant, à la face du monde, que le fils mortifié voudrait faire rendre gorge à ses parents particulièrement à son père». (Germain, 2005 :80)

Pour sauver son neveu de la rage qui s'emparait de lui, Lothar, poussé toujours par le devoir pastoral envers cet orphelin, l'a orienté vers l'étude. Ce procédé auquel Lothar a eu recours représente l'un des mécanismes de défense appelé le déplacement. «Ce mécanisme se réfère à la réorientation d'une émotion ou impulsion de son objet naturel à un autre objet, car l'exprimer vers son objet naturel serait trop pénible. Il permet de décharger des quantités d'affect en une direction moins dangereuse que l'originelle on bien dans une direction socialement acceptable ${ }^{\mathbf{}}$.

C'est grâce à son oncle que l'adolescent a appris l'anglais et l'espagnol rapidement. Le progrès de l'adolescent dans ses études a permis à son oncle de l'inscrire dans un collège où il est pensionnaire pour suivre une scolarité normale.

Le rôle éducatif de Lothar apparaît clairement quand son neveu a appris à 
travers le sursaut de mémoire qui lui est venu sous l'emprise de la fièvre, l'autre face de la réalité qui l'a réveillé d'un long mensonge flagrant pour découvrir qu'il est un orphelin qui a perdu ses parents sous les bombardements de la Seconde Guerre mondiale et que Thea n'est qu'une mère adoptive qui l'a adopté pour satisfaire son besoin impérieux d'avoir un enfant et de compenser sa privation de ses deux jeunes frères tués à la guerre. Cette réalité implacable affirme, par conséquent, que Lothar n'est pas son oncle. Arrivé au comble de l'irritation après cette découverte frappante, le jeune homme, poussé par la colère et la curiosité a couru vers Lothar qu'il croyait son oncle espérant trouver des réponses logiques à ses interrogations infinies. «Pourquoi m'avez-vous enfermé dans cette mystification? Pourquoi m'avoir menti, tout ce temps?» (Germain, 2005 : 115)

Lothar, par le bon cœur d'un pasteur, a accueilli ces questions accusatrices sans la moindre défense de sa part. Malgré la cruauté de la vérité, Lothar qui attend impatiemment le moment où le jeune homme peut sortir de ses ténèbres, n'a pas essayé de nier ou feindre l'incompréhension. Comme il savait que sa sœur Thea souffrait d'un cas de stérilité incurable, Lothar était sûr que l'enfant que sa sœur lui a confié était un enfant adoptif. Cependant; il a gardé ce secret et «il n'en avait soufflé mot à quiconque, pas même à sa femme Hannelore ou à ses filles, de peur de plomber encore davantage la tromperie en la partageant avec d'autres à l'insu de l'intéressé.» (Germain, 2005 : 119) Soucieux de l'avenir de cet orphelin, Lothar qui considérait ce secret comme un lourd fardeau, trouve une grande satisfaction quand il a arraché cet adolescent à son ignorance et à «un long mensonge par excès de discrétion» (Germain, 2005 : 116). Accablé par la découverte de ce secret, le jeune homme, qui a renoncé, à son nom Adam et a préféré celui de son ours Magnus qui lui reste de son passé, a décidé de quitter l'Angleterre et de partir vivre aux États-Unis.

\section{3-L'influence de Lothar sur Magnus}

Lothar, malgré tout, a exercé une influence de première importance sur la vie de Magnus qui a subi une métamorphose considérable grâce à lui. Passé l'orage de la colère, Magnus, avec le temps, a compris qu'il doit témoigner toute sa reconnaissance envers Lothar et son épouse Hannelore qui étaient sa bouée de sauvetage. "C'est eux qui ont donné la chance d'un premier renouveau après le naufrage de ses faux parents fuyant leurs crimes dans des morts lamentables.» (Germain, $2005:$ 146)

Avec le temps, Magnus a également compris que c'est la dévotion et la conscience de Lothar qui l'ont empêché de divulguer le secret de «cet enfant rescapé de Gomorrhe puis accaparé et manipulé par sa sœur, Lothar avait livré seul son combat de conscience, seul face à ce Dieu qui était au cour de sa vieDieu, comme un abîme muet d'où soufflait cependant un vent faisant mugir des torsades de paroles inouïes et inaudibles». (Germain, 2005 : 146)

Toujours avec le temps, Magnus a compris que c'est Lothar qui lui a tendu la main pour le sauver de son ignorance et de ces histoires invraisemblables inventées par ses faux parents. «Déraciné, tiraillé entre plusieurs pays, cultures et langues», (Koopman, 2007 : 249) Magnus, privé d'affection et de consolation, considère le bon pasteur comme un abri auquel il peut avoir recours aux moments 


\section{Dr. Manal Zahran}

difficiles et dans les dures épreuves. Ces sentiments de gratitude que Magnus éprouve à l'égard de Lothar étaient suffisants pour qu'il rentre en Europe après une douzaine d'année d'absence et d'errance aux États-Unis pour chercher la consolation et la sécurité auprès de cet homme pieux et charitable. Rien n'est plus expressif que l'accueil chaleureux de Lothar. Par la passion d'un père tendre, Lothar accueille Magnus à bras ouverts comme s'il attendait son retour «J'étais sûr que tu reviendrais un jour, [...]. Toutes ces années, sans la moindre nouvelle de toi ... je t'ai imaginé diverses vies, j'ai espéré que tu avais trouvé l'apaisement. Et le pardon». (Germain, 2005 : 151)

Après cette longue période de rupture, le jeune homme apprécie la tendresse et la gentillesse qui émanent des yeux de Lothar qui «lorsqu'il pose son regard sur son interlocuteur, il embrasse celui-ci dans l'orbe de sa clarté». (Germain, 2005 : 155).

C'est vers le bien et la paix que Lothar oriente toujours le jeune homme. Par un cœur plein d'indulgence et de piété, Lothar prie le jeune homme de pardonner même ceux qui ont provoqué son malheur et sa souffrance afin de jouir de la paix intérieure et l'équilibre psychique. Après ces longues années de séparation, Sylvie Germain nous souligne l'intérêt que Lothar accorde au jeune homme qui reste encore à ses yeux un enfant orphelin qui a besoin d'instruction et d'orientation. Ce sentiment de responsabilité pousse Lothar, inquiet du sort du jeune homme, à lui demander s'il est croyant. A cette interrogation qui paraît bizarre et stupéfiante pour le jeune homme, il répond désespérément au pasteur «Il m'est déjà assez difficile d'avoir foi en moi-même et en les autres». (Germain, 2005 ; 155). Gêné par ce prétexte plutôt qu'une réponse, Lothar, essayant de mettre le jeune homme sur le bon chemin, lui explique en souriant «que la foi en Dieu relève du même acte aventureux, et souvent éprouvant, que la foi en l'homme. Aucune certitude, aucun acquis et aucun repos dans cet acte de la pensée et du cour à renouveler chaque jour». (Germain, 2005 : 155)

Comme il doit sa survie, son réveil de ces illusions et ces mystifications inventées par la femme qu'il croyait sa mère, et son instruction scolaire et morale à cet homme dévot et indulgent, Magnus, pour témoigner sa gratitude pour les bienfaisances de cet homme qui «depuis quelques temps, souffre de vertiges, sa vue décline, sa voix s'essouffle vite», (Germain 2005 ; 184) essaie de payer son énorme dette en restant à l'aide de son instituteur. Pendant son séjour temporaire à Londres, le jeune homme, refusant la proposition de Lothar de l'héberger, «préfère louer un studio et lui rendre fréquemment visite que s'installer chez lui» (Germain, 2005 : 159) Lors de ses visites, Magnus, plus que reconnaissant à son éducateur dont la vue commence à s'affaiblir, et l'empêche de lire, lui propose de lui faire la lecture de ses livres préférés comme «Sermon sur la montagne dans l'Evangile de Matthieu et le Prix de la grâce de Dietrich Bonhoeffer ». (Germain $2005 ; 185)$

La relation fidèle qui lie le jeune homme à son maître et à son éducateur ne s'est pas interrompue même après son départ inattendu à Vienne. De temps en temps, Magnus tient à retourner à Londres pour visiter le handicapé qui a perdu sa vue, sa voix et sa capacité de marcher. De sa paralysie, il ne lui reste plus que, son sourire qui reflète «le fond de son être : l'intelligence et la pudeur d'une 
bonté sans souci d'elle-même». (Germain, 2005 : 204)

Influencé par son maître et son ami le pasteur Dietrich Bonhoeffer, le vieux pasteur handicapé demeurait enfermé dans son fauteuil près de la fenêtre de son bureau pensant aux paroles de ce professeur qui résonnent dans ses oreilles «Je dois avoir la certitude d'être entre les mains de Dieu et non celles des hommes Alors tout devient facile, même la privation la plus dure [...]. L'important, c'est que tout ce qui m'arrive trouve en moi la foi...»(Germain, 2005 : 208).

Tel était le cas de Lothar, sa foi en Dieu était tellement forte qu'elle lui donne la patience, le courage et la tolérance. Soumis à toutes les infirmités qu'il supportait gracieusement, Lothar est resté assis dans son fauteuil d'invalide, un bon esclave à son Dieu jusqu'au dernier moment de sa vie où il a trouvé la mort silencieuse et paisible. Ému par la mort de son ami tutélaire, Magnus est retourné à Londres pour assister aux funérailles de son tuteur. C'est le beau-fils de Lothar qui a prononcé l'allocution funèbre qui était fondée sur deux textes de la Bible chers à Lothar «Le chapitre 19 du Premier Livre des Rois où le prophète Élie monte vers L'Horeb, et le "Sermon sur la montagne» dans L'Évangile de Matthieu». (Germain, 2005 : 205)

Le lendemain de l'inhumation, et avant de partir à Vienne, Magnus a reçu une boîte hermétiquement fermée de Myriam la petite-fille de Lothar. Sous la pression de Myriam qui l'a prié de ne pas ouvrir la boîte avant son arrivée à Vienne, Magnus, respectant le désir de l'adolescente n'a ouvert le paquet que dans l'avion pour découvrir le masque mortuaire de Lothar.

Douée pour le dessin et la sculpture, Myriam, la petite-fille qui est venue s'installer chez ses grands-parents Lothar et Hannelore pour pouvoir suivre des cours dans une école d'art à Londres loin de sa famille nombreuse, a exécuté cette œuvre d'art par ses doigts talentueux exprès pour Magnus afin que Lothar reste toujours dans sa mémoire. La vie de ce pasteur était comme nous décrit Martin Luther King «La vie d'un homme Saint consiste plus à recevoir de Dieu qu'à donner, plus à désirer qu'à posséder, plus à devenir pieux qu'à être pieux». (Germain, $2005:$ 207)

\section{III-Frère Jean (L'autorité religieuse) \\ 1-L'apparition fortuite de frère Jean}

Saisi par un état de malaise, de mélancolie et de détresse après la mort de son ami tutélaire Lothar, Magnus que lui manque une sagesse de sédentaire, décide de quitter Vienne et de partir sans destination précise. Cet état d'errance correspond à la définition de l'errance géographique comme «un déplacement d'une durée plus ou moins indéfinie, dans un espace plus ou moins dépourvu de limites, en fonction d'un itinéraire plus ou moins indéterminé.» (Barthélemy, 1992 : 149). Cet état d'errance géographique apparaît clairement quand le jeune homme, encombré de son passé gênant et de ses souvenirs douloureux, «cherche un endroit neutre, et reculé, un lieu - clepsydre où laisser passer le temps, jusqu'à ce que son tour vienne» (Germain, 2005 : 232). Cette fuite correspond à ce que Paul Ricœur appelle «La mémoire empêchée. Le sujet, pour des raisons pathologiques et psychologiques refoule des souvenirs qui seraient trop 


\section{Dr. Manal Zahran}

douloureux pour lui. Les souvenirs sont là, mais maintenus, éloignés de la conscience par un phénomène de censure, de barrière». (Ricœur, 2003 : 83)

Après une grande hésitation, son choix s'arrête sur la France où il préfère s'éloigner des villes avec leurs vacarmes et leurs foules pour aller s'installer près d'un petit village nommé Bazoches dans une claustration volontaire à l'intérieur d'une petite maison accolée à une grange et une étable. Recroquevillé sur soimême, Magnus est resté isolé de tout le monde refusant toute relation avec les autres jusqu'à l'apparition de frère Jean dans sa vie. Le personnage de frère jean qui occupe quelques pages à la fin du roman, représente la voix de la religion chrétienne que Sylvie Germain tient à incorporer dans le roman pour mettre son héros sur le bon chemin après une vie d'errance et de vagabondage. Dans ce sens, Katherine Roussos nous déclare que «Sylvie Germain embrasse un christianisme syncrétique et personnel, influencé par de grandes traditions mystiques». (Roussos, 2007 : 83). Et un peu plus loin elle ajoute que «Sylvie Germain exprime une vision plutôt positive des religions dominantes, [...]. S'inspirant souvent de la Bible, ses récits sont à la fois contemporains et intemporels. Docteur en philosophie, Germain s'interroge sur l'identité de Dieu et son influence sur le monde. Les croyances des personnages, inspirées par le christianisme et le judaïsme, s'écartent des dogmes. La quête de Dieu est surtout une quête de soi». (Roussos, 2007 : 188) Quant à Anne - Claire Bello nous déclare que «le héros préférera s'engager dans d'autres explorations pour accéder à ses racines célestes, filiations de pure transcendance. La trajectoire du roman est donc de passer d'une filiation terrestre - axe paradigmatique d'une logique de la race, $d u$ sang, du lignage et de l'atavisme à une filiation spirituelle axe syntagmatique de l'oubli de soi, du lignage, de l'héritage et de l'hérédité - qui seule peut conduire à l'autonomie, à la liberté et à l'identité». (Bello, 2011 : 105-106)

En principe, Sylvie Germain a déjà présenté frère Jean sous le nom de Blaise Mauperthuis ou Blaise - le - Laid qui figure dans son roman Jours de Colère. Blaise Mauperthuis est l'un de ces neuf fils divins de Ephraïm Mauperthuis qui malgré le refus de son père Ambroise Mauperthuis, a insisté à se marier avec l'obèse et dolente Reine Verselay. Ce mariage bénit a donné naissance à neuf fils qui «Bien qu'ils soient tous nés avec un an d'intervalle, le 15 août, ils apparaissent comme nés le même jour». (Germain, 1989: 84). Persécutée par le grand-père Ambroise Mauperthuis, cette famille nombreuse jouissait «d'une foi syncrétique, qui attribue à Reine un statut de déesse-mère et d'assimilation à la Vierge Marie, et à ses neuf fils celui d'anges des bois». (Roussos, 2007 : 232).

Frère Jean a rencontré Magnus trois fois successives. La première rencontre était près de la grange de la petite maison qu'il a louée pour s'y installer. Stupéfait par l'apparence excentrique du vieux religieux dès la première rencontre, le jeune homme a eu l'impression qu'il est devant une vieille femme comme nous révèle l'écrivaine « [...]. Magnus aperçoit une vieille femme assise près de la porte de la grange. Elle porte un chapeau de paille informe, une robe à la couleur indéfinie tant elle est usée, et des galoches crottées. [...]. Magnus pense qu'il s'agit certainement d'une vieille à l'esprit divagant qui s'est égaré et s'est installée là, se croyant chez elle. [...]. Une allure de brave sorcière sortie 
d'un livre de contes, se dit Magnus». (Germain, 2005 : 243) Pour corriger la pensée du jeune homme, le vieux religieux ôte son chapeau, découvrant sa vraie personnalité et sa passion pour les abeilles qui l'accompagnent partout comme il déclare à Magnus. "J'ai choisi le meilleur en ce monde, vois-tu, la compagnie des abeilles, [...]. Il tend ses paumes abeillées devant Magnus et lui dit : Dans la ruche leur souveraine est entourée [...] par une cour très affairée de servantes et d'ouvrières. Mais pour moi, elles sont toutes des reines, surtout les ouvrières, [...]. Chacune a son office, qu'elle remplit de bout en bout de sa courte existence, sans faillir. Regarde-les, mes petites reines, mes flamboyantes! Les demoiselles d'honneur du soleil...» (Germain, 2005 : 244)

Cette passion pour les abeilles, Sylvie Germain l'a déjà évoquée dans son roman Jours de Colère «Blaise le - Laid (le seul lettré) préfère célébrer les fêtes religieuses «parmi ses abeilles» qu'à l'église». (Germain, 1989: 85) Lors de cette première rencontre, le vieil apiculteur, essayant de faire la connaissance du jeune séquestré, lui révèle son nom et lui demande le sien. Rien n'est plus expressif que le ton placide avec lequel le vieux moine a émis son premier message quand le jeune homme lui a déclaré qu'il a oublié son nom «le moine clownesque ne semble, lui nullement étonné par cette réponse. «Cela arrive. Et c'est bon signe» (Germain, 2005 : 245) Et un peu plus loin, le vieux religieux ajoute. «Bah, les noms ... il arrive qu'on en change au cours d'une vie, comme si celui qu'on a reçu à la naissance n'était pas le bon». (Germain, 2005 : 255)

Cette froideur biaise avec laquelle le vieux moine exprime son opinion sur l'anonymat du jeune homme traduit l'insignifiance des noms et leur incapacité à donner une valeur à ceux qui les portent et par conséquent l'oubli qui le gêne ne doit ni le consterner ni perturber sa vie. Pour consoler le jeune homme et apaiser ses malheurs, le vieux moine lui dévoile son vrai prénom Blaise qu'on lui a enlevé et son nouveau prénom Jean qu'il n'a pas choisi au monastère. Dans ce cadre Nadine Vasseur révèle «des noms de famille qu'on se lègue comme des bijoux, ou au contraire un nom en toc ... il y a toujours dans cette transmission quelque chose qui renvoie à la précarité du sentiment de soi. Il n'est pas sûr qu'il soit plus difficile de s'y retrouver au détour d'une piste brouillée que d'être un maillon serré dans la succession des générations». (Vasseur, 1996 : 103)

Quant à Hélène Chareyron, elle affirme que «Retrouver le nom perdu ne revient pas à sauver le sujet d'une perte irrémédiable. Le nom effacé n'est pas une catastrophe, il est aussi un trajet, une antépénultième étape d'un voyage engagé par le personnage au nom incertain, taraudé par la crainte de l'anonymat» (Chareyron, $2013: 519$ )

\section{2-Le rôle de frère Jean}

En principe, le rôle de ce personnage dans la vie de Magnus consiste à l'aider à sortir de ses ténèbres et à passer de la filiation terrestre qu'il ignore à la filiation céleste qui peut compenser son anonymat, son identité perdue et l'aider à trouver l'apaisement, la consolation et la paix intérieure. Avant de braquer la lumière sur le rôle de ce vieux religieux dans la vie de Magnus et ses tentatives de tendre ses mains à cette personne recluse afin de l'attirer de son désespoir et de sa réclusion, nous avons essayé d'établir une comparaison entre leur vie sous forme 


\section{Dr. Manal Zahran}

d'un tableau exposant la ressemblance des circonstances et des défis qu'ils affrontent et la différence de la capacité de chacun à surmonter ces épreuves.

\begin{tabular}{|c|c|c|}
\hline Éléments de comparaison & Frère Jean & Magnus \\
\hline 1-La famille & $\begin{array}{l}\text { «Ma fratrie était grande- } \\
\text { neuf garçons, [...] } \\
\text { A présent ils sont tous morts, } \\
\text { tous partis saluer } \\
\text { l'Immaculée Mère de Dieu. } \\
\text { Bientôt ce sera mon tour» } \\
\text { (Germain, } 2005: 252)\end{array}$ & $\begin{array}{l}\text { Magnus a perdu ses parents } \\
\text { biologiques pendant la } \\
\text { Seconde Guerre mondiale et } \\
\text { «il ne veut plus entendre } \\
\text { résonner en lui les noms } \\
\text { exécrés de Thea et Clemens } \\
\text { Dunkeltal (ses parents } \\
\text { adoptifs) et tous leurs } \\
\text { pseudonymes puant le } \\
\text { mensonge et le crime» } \\
\text { (Germain, } 2005: 246 \text { ) }\end{array}$ \\
\hline 2-La solitude & $\begin{array}{l}\text { "Voilà une trentaine } \\
\text { d'années que je vis en ermite, } \\
\text { à proximité de mon } \\
\text { monastère jamais je n'aurais } \\
\text { pu tenir si j'avais eu un cour } \\
\text { aussi assombri que le tien" } \\
\text { (Germain, } 2005: 254)\end{array}$ & $\begin{array}{l}\text { «tu es un reclus, pas un } \\
\text { ermite. Un esseulé, pas un } \\
\text { solitaire ». } \\
\text { (Germain, } 2005: 254)\end{array}$ \\
\hline 3-L'activité & $\begin{array}{l}\text { «J'élève des abeilles, [...], } \\
\text { j'apporte le miel au } \\
\text { monastère en échange je } \\
\text { reçois de quoi manger, me } \\
\text { vêtir». } \\
\text { (Germain, 2005 : 254) }\end{array}$ & $\begin{array}{l}\text { " Enfermé, prisonnier } \\
\text { emmuré, pétrifié dans sa } \\
\text { grange ». } \\
\text { (Germain, } 2005: 254 \text { ) }\end{array}$ \\
\hline 4-L'anonymat & $\begin{array}{l}\text { «J'ai dî quitter le mien (son } \\
\text { nom) quand je suis entré au } \\
\text { monastère, [...]. Mon } \\
\text { prénom était Blaise on me l'a } \\
\text { enlevé, tu t'appelleras frère } \\
\text { Jean, on m'a dit». (Germain, } \\
2005: 255 \text { ) }\end{array}$ & $\begin{array}{l}\text { «Magnus ne retrouve pas son } \\
\text { nom [...]. Il se sent frappé } \\
\text { d'anonymat comme on est } \\
\text { frappé par un coup, par un } \\
\text { mal, la maladie de la perte». } \\
\text { (Germain, 2005: 245). }\end{array}$ \\
\hline 5-La foi & $\begin{array}{l}\text { «[...], comme le Baptiste } \\
\text { [..], ou comme l'Evangéliste. } \\
\text { [...]. Moi, je ne suis qu'un } \\
\text { tout petit Jean, et l'Ange du } \\
\text { Verbe m'a fissuré la lèvre en } \\
\text { me clouant son secret sur la } \\
\text { bouche [..] sur ma lèvre } \\
\text { fendue» (Germain, } 2005 \text { : } \\
\text { 255) }\end{array}$ & $\begin{array}{l}\text { «je ne suis pas croyant. » } \\
\text { (Germain, } 2005: 256)\end{array}$ \\
\hline
\end{tabular}

D'après cette comparaison, nous pouvons conclure que les deux personnages Magnus et frère Jean ont vécu les mêmes circonstances et les mêmes 
dures épreuves mais la foi en Dieu qui distingue frère Jean l'a aidé à supporter les malheurs et les peines de la vie sans tomber dans le labyrinthe d'errance et du désespoir. Essayant de faire sortir Magnus de sa prison qui a duré près de trois ans dans la grange, le vieux religieux a dormi plusieurs fois dans l'étable qui se trouve juste à côté de la grange où Magnus reste des heures et des heures enfermé afin d'attirer l'attention du prisonnier qui n'a jamais remarqué sa présence. Désespéré de briser la solitude et le silence de ce reclus, «le moinillon coiffé de sa ruche ambulante est revenu» (Germain, 2005: 251) pour lui imposer une deuxième rencontre. Profitant de la fête du 15 août qui est le jour de l'Assomption de Marie et en même temps celui de son anniversaire, le vieil ermite, préparant un déjeuner à côté de la grange, a invité le séquestré à ce repas frugal en cet honneur comme il révèle à Magnus "C'est qu'aujourd'hui, nous sommes le 15, jour de l'Assomption de Marie.[...]. Et tu sais quoi ? C'est aussi mon anniversaire. Je suis né une nuit de 15 août, [...]. »(Germain, 2005 : 252)

Le vieil ermite est donc l'un des fils du soir qui selon Katherine Roussos «sont basanés, mélancoliques, excentriques et fantaisistes, avec des qualités plutôt mentales ou créatives que physiques. Ils ne sont pas bûcherons, mais artisans, travaillant merveilleusement le bois. [...], ils privilégient la mélodie». (Roussos, 2007 : 192). Telles étaient les qualités de frère Jean qui éprouve un penchant irrésistible vers le chant comme nous le révèle l'auteure vers la fin du roman «Le frère Jean se met à chanter, sa voix est restée mélodieuse. Il psalmodie la litanie de la Vierge, en latin». (Germain, 2005 : 257). Et un peu plus loin l'auteure nous révèle que «Frère Jean, un moine buissonnier qui aura fait montre autant d'extravagance que de discrétion, d'ingénuité que d'insoumission». (Germain, 2005 : 272) Pour convaincre Magnus de renoncer à sa vie terrestre et de penser à sa vie céleste le vieil ermite au cœur apicole, manifestant une foi pure et une dévotion totale à la Vierge, commence à lui expliquer l'importance de la fête du 15 août le jour de l'Assomption de Marie et aussi celui de la naissance de tous les enfants de sa famille qui considérait cette coïncidence des dates une bénédiction «Tous les enfants sont nés un 15 août.[...]. Tous venus au monde sous la protection de la Vierge. Alors cet anniversaire, ce n'est pas seulement le mien, c'est aussi celui de mes huit frères.» (Germain, 2005: 252) déclare le vieux moine à Magnus.

Cette explication était suivie d'un long discours prophétique sur le grand don de Dieu qui est la vie. Avec la dévotion d'un homme pieux et croyant, le bonhomme s'est mis à éclaircir au jeune homme désespéré la valeur et l'intérêt de la vie. Rien ne peut nous aider à supporter l'amertume de la vie que la foi en Dieu qui nous rend moins libre mais plus heureux. Dans cette optique, le vieux moine compare le chemin vers Dieu à un délicat labyrinthe qui ressemble «à l'ingénieux système inventé par Vauban pour assiéger une ville fortifiée, consistant en tranchées souterraines tracées en ligne brisées reliées entre elles obliquement». (Germain, 2005 ; 256)

A travers cette comparaison, le vieux religieux explique au jeune homme que la vie est à la fois la prison de tout croyant et le paradis de tout athée. Soumis au pouvoir divin, l'homme croyant reste un esclave obéissant aux ordres de Dieu et par conséquent il accepte avec satisfaction sa destinée sans la moindre 


\section{Dr. Manal Zahran}

protestation de sa part. Par contre l'homme athée, niant l'existence divine, reste un esclave à ses désirs, ses convoitises et ses bas-instincts toujours inassouvis et ne pense ni à sa fin ni au châtiment de son créateur.

Pour attirer le jeune homme vers l'univers céleste, le vieil apiculteur avant son départ, lui a promis de lui envoyer ses abeilles pour l'emmener chez lui. «La prochaine fois, c'est toi qui viendras à moi. [...]. Aucun souci, je t'enverrai mes abeilles. Tu n'auras qu'à les suivre». (Germain, 2005 : 257)

La promesse du vieil apiculteur était une parole d'honneur. Vers la fin de l'été, les messagères de l'ermite sont arrivées chez le jeune homme pour l'accompagner à la clairière où frère Jean l'attendait. Après avoir accueilli l'invité, le vieil ermite, gardant le silence, invite le jeune homme à écouter la voix divine représentée par la nature alentour «la forêt alentour bruit de multiples sons sur fond du sourd bourdonnement des ruches; frémissements des feuillages, froissements des herbes, craquements de brindilles sèches, petits cris perçants ou appels flûtés lancés par des oiseaux, chuchotis et sifflements du vent, et par instants, des aboiements de chiens et des échos de voix humaines dans le lointain». (Germain, 2005: 265)

Toutes ces créatures ne sont que des preuves et des témoignages qui manifestent et affirment l'existence, le pouvoir et la majesté du créateur. Tel était le message silencieux émis par le vieil ermite qui demande au jeune homme de suivre visuellement et auditivement la chute des feuilles d'un arbre et d'essayer de distinguer «le souffle infime d'une feuille qui tombe sur fond des divers bruits de la forêt et de la basse continue des ruches»(Germain, 2005 : 266). Après cette longue méditation auditive, le vieil ermite, lors de cette troisième rencontre silencieuse entre en somnolence qui le sépare complètement du monde terrestre et le transporte au monde céleste où il peut voir des visions de Dieu. «Ainsi enveloppé dans sa chrysalide noire, il entre en somnolence. Sa tête dodeline, elle finit par basculer contre l'épaule de Magnus; sa respiration s'altère, elle se fait à la fois plus sonore et alentie - Rien de plus - aucun flamboiement, aucune agitation du corps assoupi, aucun râle, ni bredouillement proférés par sa bouche». (Germain, 2005 : 266)

Dans Jours de colère, Sylvie Germain déclare que les neuf frères avaient l'habitude d'entrer en somnolence. «La foule écoutait, tout à la fois recueillie et somnolente dans la clairière enivrante de chaleur et d'odeurs et de bourdonnements de mouches et de guêpes. Beaucoup semblaient s'endormir debout, en douceur. Les têtes dodelinaient, les paupières, s'alourdissaient.» (Germain, 1989 : 96-97).

A ce propos Katherine Roussos révèle les habitudes et les valeurs incarnées par les neuf frères qui préfèrent entrer dans cet état de somnolence que d'écouter les discours prophétiques des prêtres à l'église, «les sermons font plutôt dormir qu'éveiller à une conscience de Dieu. En revanche, leur douce somnolence les éveille à une autre conscience, également divine, celle de le nature alentour.» (Roussos 2007 : 194) Et un peu plus loin, elle ajoute «La clairière " enivrante» contraste avec les prédicateurs assommants; le bourdonnement des insectes est plus captivant que les mots du prêtre». (Roussos, 2007 : 194)

Éveillé de sa somnolence, le vieux moine, avouant sa satisfaction de sa vie 
et son patriotisme, demande à Magnus en lui serrant les bras de rentrer chez lui et de ne pas revenir à la clairière qu'après sa mort qui est très proche.

\section{3-L'influence de frère Jean sur Magnus}

L'apparition fortuite de ce moinillon dans la vie de Magnus était une source de gêne, d'ennui et de dérangement pour lui. Après près de trois ans de claustration dans la grange de la maison où il s'est installé, Magnus a découvert qu'il est observé par un inconnu qui s'efforce curieusement de pénétrer dans sa vie. Espérant trouver la paix en vivant en reclus, Magnus, refusant l'existence de cet importun, s'est mis en colère «de se découvrir espionné par ce vieux fouineur». (Germain, $2005: 254)$

Malgré la courte durée qu'il a passée avec le jeune homme, frère Jean a exercé une influence de première importance sur lui. La patience de frère Jean ainsi que sa persévérance et sa foi l'ont aidé à faire sortir cette âme désespérée et attristée de ses ténèbres. Dès sa première rencontre aléatoire avec le vieil apiculteur, Magnus a eu l'impression «de se trouver devant un clown jonglant avec des insectes apprivoisés autant qu'avec des mots bizarres, ou plutôt, devant un épouvantail soudain doué de mouvement et de parole, et il se demande d'où il sort et ce qu'il lui veut». (Germain, $2005: 245$ )

Rien n'est plus frappant que la stupeur qui a saisi le jeune homme quand le vieux moine lui a demandé son nom. Incapable de répondre à cette question tellement simple, le jeune homme. "se sent frappé d'anonymat comme on est frappé par un coup, par un mal. La maladie de la perte, [...]. Est-ce là tout le résultat de son long travail de décantation opéré dans la solitude des chemins, des forêts, dans le silence de la grange?» (Germain, 2005 : 245)

Cette première rencontre avec le vieil ermite avait une influence considérable sur le jeune homme qui, en quête de son nom, est retourné dans la grange proie facile à être dévorée par ses souvenirs et par tous les personnages qu'il a rencontrés au cours de sa vie. Hanté par tous les personnages qu'il a connus, le jeune homme s'est mis à les appeler «chaque nom a sa carnation, son allure, son timbre, et un léger frémissement.[...]. Chacun a son éclat, sa résonance singulière. [...]. Mais son propre nom est absent». (Germain, 2005 : 247)

Après une nuit de délire et de lutte avec soi-même et sous la pression de la fatigue, le jeune homme, toujours en quête de son nom, écrit au bout de son index dans la poussière un autre nom qui lui est totalement étranger. Ce nom n'a pas duré longtemps, malheureusement en se levant le matin, le jeune homme l'a effacé et n'a laissé de sa signature qu'une seule lettre un L qui a excité sa curiosité et l'a jeté dans l'embarras de nouveau en quête de son nom oublié.

Quant à la deuxième rencontre où le vieil ermite a invité Magnus au déjeuner, était très ennuyeuse et gênante pour le jeune homme. Etourdi par le bavardage de l'importun sur la fête de la Vierge, l'Ange du Verbe et le don de Dieu, le jeune homme se trouve incapable de comprendre les discours prophétiques infinis de frère Jean. «Magnus a l'impression d'avoir été introduit subrepticement dans un conte. Un conte désuet intercalé par inadvertance dans le 


\section{Dr. Manal Zahran}

roman décousu de sa vie». (Germain, 2005 : 257)

Cependant, Magnus était influencé par les opinions de ce vieil apiculteur. Convaincu par les paroles du vieil ermite qui l'encourage à renoncer à sa solitude et à mettre fin à son silence, le jeune homme décide de sortir de son vide et de sa réclusion et de partir, mais l'arrivée des abeilles pour l'emmener chez le vieil apiculteur a interrompu son départ. Dès l'arrivée de l'essaim, Magnus a hésité «à prendre au sérieux la promesse fantaisiste de l'ermite» (Germain, 2005 :264) qui lui a promis de lui envoyer ses abeilles pour l'accompagner. Cependant il a pris sa décision de répondre à l'appel du vieux moine et de suivre ses éclaireuses pour aller le rencontrer. Rien n'est plus expressif que l'obéissance totale et la résignation absolue du jeune homme aux ordres du vieil ermite quand ce dernier lui a demandé de concentrer et d'essayer d'écouter le son de la chute d'une feuille d'arbre «aussi fine qu'une aile d'insecte, atteint le sol à quelque distance de lui.» (Germain, 2005 :266)

Après plusieurs tentatives, le jeune homme a réussi à suivre ce processus. De même Magnus est entré en somnolence avec le vieil ermite. «Les deux hommes sont si totalement abandonnés dans l'écoute de ce soupir et si unis dans cet abandon que Magnus en est bouleversé». (Germain, 2005 :267)

L'obéissance de Magnus atteint son paroxysme quand il a suivi les recommandations du vieil ermite qui lui a conseillé de revenir à la clairière après sa mort. Deux jours après la dernière rencontre, le jeune homme, sans aucun appel est allé tout seul à la clairière pour découvrir une fosse étroite et assez profonde où est couché frère Jean tenant «son chapelet enroulé autour de ses mains croisées sur la poitrine» (Germain, 2005 :271)

Respectant les recommandations du défunt, Magnus, après avoir comblé la fosse de frère Jean, a rendu sa coule à l'abbaye et a assisté à l'office célébré à sa mémoire. Lors de cet office, l'abbé a honoré l'ermite Blaise Mauperthuis tout en signalant sa vive passion pour la nature et les abeilles «qu'il a tellement aimées au point de choisir de reposer parmi elles, au fond d'un bois-, et qui gravitait toujours autour du monastère, y apportant ses pots de miel et des nouvelles des arbres, des oiseaux, des bêtes sauvages dont il était devenu plus proche que de ses frères en religion». (Germain, 2005 : 272)

De même, le prêtre n'a pas manqué d'évoquer pendant cette cérémonie organisée à l'hommage du défunt, sa dévotion sincère à la Vierge qui le pousse d'aller un jour à l'abbé pour lui prévenir le vol de la statuette de la Vierge de sa clairière. Soumis à cet accident de cambriolage, le vieil a décidé que «l'absence de statuette célébrait dorénavant Notre - Dame du Vide». (Germain, 2005 : 273)

En outre, le vieux moine a demandé à l'abbé d'aller bénir cette non statue. Ainsi par la mort de frère Jean, Magnus tourne la dernière page de ce personnage et retourne à la grange pour chercher ses bagages et partir sans destination précise. Pour rompre toute relation avec le passé, Magnus a enterré le masque mortuaire de Lothar sous la tilleul sous lequel frère Jean a préparé le déjeuner du 15 août. Quant à l'ours en peluche avec lequel il partage son nom, Magnus l'a livré «aux eaux du Trinquelin, petit torrent qui coule au pied de l'abbaye». (Germain, 2005 :274) 


\section{Conclusion}

Ainsi, nous avons étudié à travers cette recherche trois figures différentes de l'autorité masculine dans Magnus de Sylvie Germain et leur influence sur le protagoniste du roman. La première figure est celle du mal, la figure négative représentée par le médecin nazi Clemens Dunkeltal. Congénitalement égoïste et opportuniste, Clemens ne pense qu'à ses intérêts personnels au détriment des autres même au détriment de sa femme Thea qui l'a tant aimé et son fils adoptif qu'il n'a jamais aimé. Quant à la deuxième figure de l'autorité masculine c'est celle du bien la figure positive représentée par Lothar Schmalker qui a aidé Magnus à découvrir la vérité et les mensonges inventés par ses parents adoptifs. De même, nous avons braqué la lumière sur la troisième figure de l'autorité masculine qui figure dans le roman c'est celle de la religion représentée par frère Jean ce vieil ermite qui a aidé le jeune homme à renoncer à son passé et au monde terrestre et à passer au monde céleste espérant trouver la paix perdue dans la vie. Cette modeste étude sur Magnus de Sylvie Germain nous propose d'autres questions: Quelles sont les autres figures de l'autorité masculine qui figurent dans l'œuvre de Germain et comment se présentent - elles ? Est-ce qu'il existe des figures de l'autorité féminine ? Comment l'autorité des personnages féminins se compare-t-elle à celle des personnages masculins ?

\section{I-Corpus}

\section{$\underline{\text { Références bibliographiques }}$}

- GERMAIN, Sylvie, (2005), Magnus, Albin Michel, (Prix Goncourt des Lycéens).

\section{II-Roman consulté de Sylvie Germain.}

- GERMAIN, Sylvie, (1989), Jours de Colère, Paris, Gallimard.

\section{III-Oeuvres critiques sur Sylvie Germain}

- BELLO, Anne - claire, (2011) de la filiation terrestre à la filiation céleste dans Magnus de Sylvie Germain, dans Héritage, filiation, transmission configuration littéraires $\left(\mathrm{XVIII}^{\mathrm{e}}-\mathrm{XXI}^{\mathrm{e}}\right.$ siècles), Christian Chelebourg, David Martens, Myriam Watthee - Delmotte, Presses Universitaires de Louvain.

- DOTAN, Isabelle, (2008) «Les échappés tragique de la douleur», dans Alain Goulet (dir), L'univers de Sylvie Germain, Caen, Presses Universitaire de Caen.

- GOULET, Alain, (2008) L'univers de Sylvie Germain, Caen, Presses Universitaire de Caen.

- KOOPMAN - THURLINGS, Mariska, (2007) Sylvie Germain. La hantise du mal, Paris, l'Harmattan, «critiques littéraires».

- ROUSSOS, Katherine, (2007) Décoloniser L'imaginaire, Du réalisme magique chez Maryse condé, Sylvie Germain et Marie Ndiaye. L'Harmattan, Paris. 


\section{Dr. Manal Zahran}

\section{IV-Ouvrages généraux}

- BARTHÉLEMY, Guy, (1992) «L'errance comme problème », Elseneur, no. 7, Juin.

- BELLEMIN-NOEL, Jean, La psychanalyse du texte littéraire, Introduction aux lectures critiques inspirées de Freud, Paris, Nathan, 1999.

- BERTHET, Dominique, (2007) Figures de l'errance, Paris, L'Harmattan, «ouverture philosophique».

- FREUD, Sigmund: (2003) Die Traumdeutung (1899-1900), trad : «'interprétation du rêve» dans œuvres complètes, T. IV, PUF.

- LA PLANCHE, Jean et Pontalis, J.B, (1996) : Vocabulaire de la psychanalyse, Presses universitaires de France, Editions Delta.

- MARCELLI, Daniel, (2009) !Il est permis d'obéir, l'obéissance n'est pas la soumission, Edition Albin Michel

- MUCCHIELLI, Alex, (1993): La nouvelle psychologie, Presses universitaires de France.

- NADINE, Vasseur, (1996) Le poids et la voix, Paris, le temps qu'il fait.

- RICEEUR, Paul (2003) : La mémoire, L'Histoire, l'oubli (2000). Paris, Seuil, « Point Essais ».

- SAMALIN, Nancy, (1996) Conflits Parents-enfants : comment maintenir le dialogue, France, Flammarion.

\section{-V-Thèse et mémoire sur Sylvie Germain}

- CHAREYRON, Hélène, (2013) Echos d'enfance. Les territoires de L'enfance dans l'œuvre de Sylvie Germain, Thèse de Doctorat, sous la direction de monsieur le professeur Jacques Poirier. Université de Bourgogne.

- ROGOWSKA, Edyta, (2009) Trois modèles de femmes errantes dans Magnus de Sylvie Germain, Mémoire, sous la direction de Jane Everett, Université McGill, Montréal, Août.

\section{-VI- Documents électroniques}

- www.Toupie. org/dictionnaire/Nazisme.htm.

- $\quad$ https ://Fr.wikipedia.org/wiki Ralfe.

- $\quad$ Fr/4271/2 - le régime - totalitaire - nazi htm. $\neq$ Document $=18703$.

- Fr.wikipedia.org/wiki/condition des femmes sous le troisième Reich.

- Fr.wiki pedia. org/wiki/Troisième Reich.

- www.consulta backeland.com/P/Fr/psychologue - madrid - faqs/ mécanismes - de - défense.ph.p.

- http://fr, wikipedia . org/w/index.php ? title = sermon - sur $-1 \mathrm{la}-$ montagne \& oldid $=112118160$.

- http : // www.maison bible, net/ab 1344 vivre - en - disciple - le prix de la grâce - œuvres de dietrich - bonhoeffer - vol - 4 .

- https : // www. Bible. Com/versions/133 - pdv - bible - parole - de vie.

- $\quad$ https:// frm.wiki pedia. org/wiki/Mein - Kampf. 
- https : //es m. wiki pedia. org/wiki/Pedro - Páramo $\neq$ cite -note- 1

- https://fr. m. wikipedia. org/wiki/Dietrich - bonhoeffer.

- https :// fr. wiki pedia. org/wiki/Eglises - luthériennes - d\%27 Allemagne

- face - au nazisme $\neq$ bibliographie

\section{VII-Dictionnaires}

- Dictionnaire du français, sous la direction de Philippe Amiel, Hervé Du Bourjal et Brigitte Vienne, Paris, 1989.

- Micro Robert, Dictionnaire du français primordial, sous la direction de Paul Robert, Alain Rey et Josette Rey - Debove, Paris, 1986.

\footnotetext{
1 - Sylvie Germain, est née en 1954 à Châteauroux. Au cours des années 1970, elle suit des études de philosophie, auprès d'Emmanuel Levinas à Nanterre. Dès 1983, alors qu'elle travaille au ministère de la culture à la direction de l'audiovisuel, elle envoie chez Gallimard le manuscrit de son premier ouvrage, un recueil de nouvelles, qui ne sera pas publié.

L'écrivain Roger Grenier lit ce manuscrit, l'encourage, mais lui propose de publier d'abord un roman d'elle. Sylvie Germain suit ses conseils et publie le Livre des Nuits suivi de Nuit -

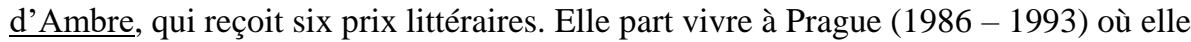
enseigne la philosophie et le français au lycée français. Les années praguoises sont l'occasion de l'écriture puis de la publication en 1989 de Jours de Colère, qui reçoit le prix Femina. En 1993, Sylvie Germain retourne en France. Elle vit alors entre Paris et la Rochelle mais Prague est le thème de son roman Immensités, En 2002 paraît un nouveau roman, La chanson des Mal-aimants. Magnus, paru en 2005 reçoit un accueil enthousiaste du public et le prix Goncourt des lycéens. Puis elle publie encore L'Inaperçu (2008) et Hors champ (2009). www.franceinter. Fr/personne - Sylvie - germain - 0

2 - La femme national - socialiste doit se conformer à la société allemande voulue par Adolf Hitler, racialement pure et physiquement robuste. Elle ne travaille pas, vit dans le culte de la maternité et suit l'adage de l'ancien empereur Guillaume II «Kinder, Küche, Kirche», soit «les enfants, la cuisine et l'église». Dans un texte publié en mai 1934, Hermann Göring résume le rôle futur de la femme allemande : «Prends une poêle, un ramasse - poussière et un balai et épouse un homme.» Il s'agit d'un anti-feminisme dans le sens où les nazis considèrent que les droits politiques octroyés aux femmes ne sont pas compatibles avec sa nature de génitrice, seul rôle dans lequel elle peut s'épanouir et servir au mieux l'intérêt de sa nation.

Fr.wikipedia. org/wiki/condition des femmes sous le troisième Reich.

3 - En juillet 1933, le régime adopte une loi sur la stérilisation forcée, conforme à son objectif de «purifier la race aryenne. Des dizaines de milliers de personnes en sont victimes. Elle concerne surtout les malades mentaux, mais aussi des Tziganes, ou encore des Noirs. En 1937, Hitler ordonne de stériliser les 400 enfants nés dans les années 1920 de soldats noirs français et de femmes allemandes.

Fr.wikipedia. org/wiki/Troisième Reich.
}

4 - Mein kampf (ou Mon combat, en français) est un ouvrage rédigé par Adolf Hitler entre 1924 et 1925 pendant sa détention à la prison de Landsberg. Il contient des éléments 


\section{Dr. Manal Zahran}

autobiographiques, l'idéologie politique du nazisme, l'histoire des débuts du NSDAP et diverses réflexions sur la propagande ou l'art oratoire.

https://fr.m.wikipedia. org/wiki/Mein-Kampf.

5- Dietrich Bonhoeffer, né le 4 février 1906 à Breslau, exécuté le 9 avril 1945 au camp de concentration de Flossenbürg, est un pasteur luthérien évangélique, théologien, écrivain et résistant au nazisme. Il appelle les croyants à la résistance et il est prêt à risquer sa vie en s'opposant à Hitler et en aidant les Juifs dans leur fuite. Bonhoeffer n'accepte pas la possibilité d'évasion qui lui est proposée et après l'attentat du 20 Juillet 1944 contre Hitler, il est transféré en octobre 1944 dans les prisons de la Gestapo, jugé coupable et condamné à la pendaison dans le camp de concentration de Flossenbürg.

https: //fr.m. wikipedia. org/wiki/Dietrich - Bonhoeffer.

6 - www.consulta backeland.com/P/FR/psychologue- madrid-faqs/mécanismes-dedéfense.ph.p 


$$
\begin{aligned}
& \text { من خلال "ماجنس" للكاتبة سيلفي جرمان } \\
& \text { د.منال زهران -مدرس بكلية التربية -جامعة عين شمس -قسم اللغة الفرنسية }
\end{aligned}
$$

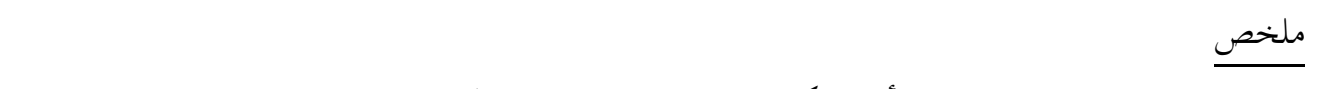
تعتبر سيلفي جرمان واحدة من أهم الكاتبات الفرنسيات اللاتي بنحن، بفضل قدراقن الإبداعية، على إثراء الأدب الفرنسي من خلال أعمالهن الأدبية المتميزة و المتنوعة والتي تعكس براعة الكاتبة.

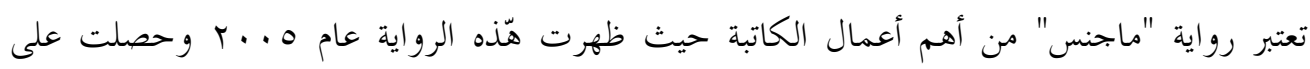
جائزة جونكور. تحاول الكاتبة من خلال هذه الرواية أن تتتبع طريق طفل يتيم وفاقد للذاكرة يحاول جاهداً أن يبجث

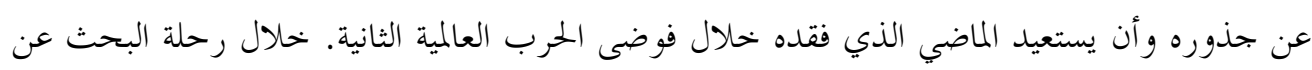
الذات هذه يقابل الطفل في جميع مراحل حياته شخصيات عديدة ومختلفة من الذكور ومن النساء. من هذه الشخصيات سوف نتناول بالدراسة والتحليل ثناثة من شخصيات الذكور الذين كانت هم

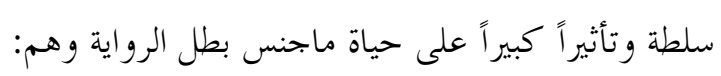

ا- سلطة الشخصية الأولى وهي سلطة سلبية تتمثل في شخصية الطبيب النازي كليمون دانكلتال الذي لا يفكر إلا في مصالحه الشخصية على حساب الآخرين دون أن يراعي مشاعر زوجته التي كانت تحبه و ابنه بالتبني الذي يرفض وجوده في العائلة.

r- سلطة الشخصية الثانية وهي سلطة ايجابية تتمثل في شخصية لوتار شمالكر الذي ساعد "ماجنس" بلني بطل الرواية على اكتشاف حقيقة الأكاذيب التي كان و الديه بالتبي يبدعون في تأليفها.

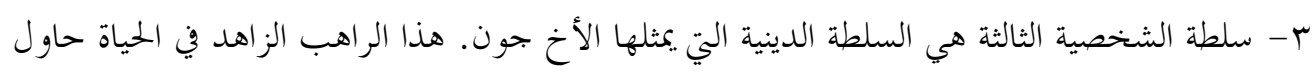

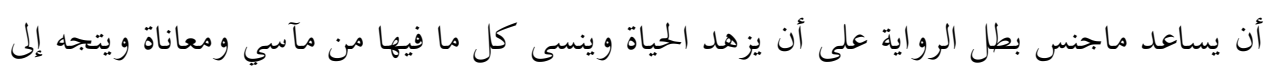
العالم الإلهي لعل وعسى يجد السعادة والإطمئنان و السكينة. وهكذا تحليل هذه الشخصيات الثلاث وتأثيرهم على الشخصية الرئيسية هو الهدف الرئيسي لهذه الار اسة. 